\title{
Evaluation of Microfluidic Approaches to Encapsulate Cells into PEGDA Microparticles
}

\author{
Kristopher A. White ${ }^{1} \cdot$ Rabab Chalaby $^{1} \cdot$ Ronke Olabisi $^{1}$ (])
}

Received: 26 July 2021 / Revised: 12 August 2021 / Accepted: 13 September 2021 / Published online: 28 September 2021

(C) The Author(s) 2021

\begin{abstract}
Purpose Polyethylene glycol diacrylate (PEGDA) is increasingly used to microencapsulate cells via a vortex-induced waterin-oil emulsion process. Herein, we evaluated methods to encapsulate cells into microparticles using microfluidic methods. Methods PEGDA prepolymer solution with or without cells was photopolymerized with white light under varying microfluidic parameters to form empty microspheres or cell-laden microparticles. Microparticles and entrapped cells were assessed for size and viability.

Results PEGDA microparticles were easily formed when cells were absent; the introduction of cells resulted in aggregation that clogged microfluidic devices, resulting in a mix of empty polymer microparticles and cells that were not encapsulated. Cells that were successfully encapsulated had poor viability.

Conclusion Microfluidic methods may work for low density microencapsulation of mammalian cells; however, when the cell density within each microparticle must be relatively high, emulsion-based methods are superior to microfluidic methods.

Lay Summary The synthetic polymer polyethylene glycol diacrylate (PEGDA) has been increasingly used to encapsulate cells into micrometer-sized hydrogel spheres (microspheres). One method to microencapsulate cells has been to form a waterin-oil emulsion with liquid polymer containing cells and then expose the suspended droplets to white light, polymerizing them into PEGDA hydrogel microspheres. Although successful, this method has poor control over the process, resulting in polydisperse microsphere sizes with varying cell density. We evaluated microfluidic methods to form both empty and cellladen PEGDA microspheres. Although microfluidic methods resulted in monodisperse microsphere sizes, the introduction of cells resulted in clogging of microfluidic devices, non-spherical microparticles, and poor cell viability.

Future Work Because the microfluidic approach successfully formed cell-free microspheres, the effect of reducing cell aggregation will be examined. Specifically, the use of anti-aggregation agents as well as a reduced cell density in the liquid polymer phase and their effects on polymer formation will be explored.
\end{abstract}

Keywords Microencapsulation $\cdot$ Microfluidics $\cdot$ Microspheres $\cdot$ Microparticles $\cdot$ Cell encapsulation

\section{Introduction}

In recent years, cell encapsulation has been increasingly explored for use in tissue engineering [1,2], regenerative medicine [3, 4], and as drug-controlled release carriers [5] for its ability to provide immunoprotection to donor cells, obviating the need for immunosuppression while offering a three-dimensional environment to the encapsulated cells [6-9]. Although alginate has long been a polymer of

Ronke Olabisi

ronke.olabisi@uci.edu

1 Department of Biomedical Engineering, University of California, Irvine, USA choice [10,11], efforts to encapsulate cells into synthetic microparticles have increased, as have approaches to effect that microencapsulation $[8,9]$. Polyethylene glycol (PEG)based hydrogels can be polymerized using a wide variety of approaches, including photopolymerization, which permits the use of photolithographic or microfluidic approaches $[8$, $12,13]$. Currently, the best described method to encapsulate cells into polyethylene glycol diacrylate (PEGDA) microspheres is a vortex-induced water-in-oil emulsion [14]. This PEGDA-emulsion method has been used to successfully microencapsulate neural stem cells [14], mesenchymal stem cells [15-17], osteoblasts [6], fibroblasts [18, 19], adenocarcinoma cells [20], and insulinoma cells [21]. The drawback of the emulsion technique is that it results in polydisperse 
microsphere sizes and there is little control over the density of cells encapsulated into each microsphere. The ability to control the density of encapsulated cells is important because certain cell types apoptose in serum-free low density cultures [22] and microencapsulation may inhibit cell access to serum proteins. We previously demonstrated that encapsulating osteoblasts into PEGDA microspheres at low cell densities results in low viability even in the presence of serum [6].

Although microfluidic approaches provide more precise control of the droplet formation process, previously described approaches using PEG have low cell densities and/or use cells that are not vulnerable to low cell densities $[20,23,24]$. If microfluidics could also successfully encapsulate cells into PEG microparticles at higher densities, it would be a promising breakthrough in scaling the process for larger scale biomanufacturing and a wider variety of cell types. The ability of microfluidic devices to control fluids at the microscale permits both a narrow size distribution of microspheres and the ability to specify hierarchical structures, mimicking the key aspects of tissue architecture [25].

Therefore, we evaluated microfluidics for (1) the optimal parameters to produce PEGDA microspheres, (2) its ability to encapsulate cells into those microspheres, and (3) its effect on the viability of cells microencapsulated using this approach.

\section{Materials and Methods}

Unless otherwise noted, all reagents were obtained from Sigma-Aldrich (St. Louis, MO, USA).

\section{Cell Culture}

Hepatocytes derived from human induced pluripotent stem cells were expanded in HepatoZYME-SFM (Life Technologies, Carlsbad, CA, USA) supplemented with hepatocyte growth factor $(25 \mathrm{ng} / \mathrm{ml})$, penicillin $(50 \mathrm{U} / \mathrm{mL})$, streptomycin $(50 \mathrm{~g} / \mathrm{mL})$, and L-glutamine $(2 \mathrm{mM})$ and incubated at $37^{\circ} \mathrm{C}$ in a humidified incubator with $5 \% \mathrm{CO}_{2}$.

\section{Microsphere Generation and Cell Microencapsulation}

\section{Reagent Preparation}

All reagents were prepared in amber tubes and wrapped in foil to protect them from light exposure and premature reaction. The droplet phase (prepolymer) was prepared as previously described [18] and consisted of a poly(ethylene glycol diacrylate) (PEGDA) prepolymer solution containing 10\% w/v PEGDA (10 kDa, Laysan
Bio, Arab, AL, USA), eosin Y (0.1 mM), 1\% w/v Pluronic $\mathrm{F} 68,1.5 \% \mathrm{w} / \mathrm{v}$ triethanolamine (TEOA), and $37 \mathrm{mM}$ 1-vinyl-2-pyrrolidinone (NVP) in $25 \mathrm{mM}$ HEPES buffered saline. The carrier phase (mineral oil) was also prepared as previously described [18], with the addition of a surfactant to prevent coalescence of the droplets in the outlet tubes. The carrier phase consisted of mineral oil containing 2,2-dimethoxy-2-2-phenyl acetophenone in NVP solution $(0.3 \mathrm{~g} / \mathrm{mL})$ and SPAN-80 $(1 \% \mathrm{w} / \mathrm{v})$. To microencapsulate cells, hepatocytes were harvested, pelleted, and combined with the droplet prepolymer solution to achieve $40 \times 10^{6}$ cells $/ \mathrm{mL}$.

\section{Microfluidic Microsphere Generation}

Prepolymer solution with or without cells was passed through a central microfluidic channel on a $195 \mu \mathrm{m}$ droplet 4-junction chip (Dolomite Microfluidics, Royston, UK) with a hydrophobic coating to prevent adherence of the droplet phase (Fig. 1).

The hydrophobic carrier phase was passed through the outer channels. Solutions were pumped with Mitos P-Pumps (Dolomite) supplied with a line pressure of air compressed to 8 bar. The solution pressures were varied from $0.2-7$ bar, and the effect on the resulting microparticles was evaluated. When cells were included, a rice sized magnetic stirrer was placed into the droplet phase chamber and rotated at $60 \mathrm{rpm}$ to prevent cell aggregation. One of the two tubes, a 1,000 and a $1,500-\mathrm{mm}$ tube $(250-\mu \mathrm{m}$ inner diameter, 1.6-mm outer diameter), was coiled into a spiral (5 and 7 turns, respectively) and placed between two mirrors to illuminate the entire coil with white light (metal halide, MH100A, Edmund Optics, Barrington, NJ, USA). The end of the coil was inserted into centrifuge tubes containing media (if cells were present) or phosphate buffered saline (if cells were absent) in which microparticles sedimented to the bottom and oil rose to the top.

\section{Emulsion Microsphere Generation}

To compare the density and viability of cells microencapsulated using microfluidic or emulsion techniques, cells were encapsulated via vortex-induced emulsion as previously described [6]. Briefly, $1 \mathrm{~mL}$ of the hydrophobic mineral oil solution was pipetted into a glass test tube, and $200 \mu \mathrm{L}$ of the cell-prepolymer solution was pipetted into the mineral oil solution. The test tube was vortexed for $2 \mathrm{~s}$ and held under white light for an additional $20 \mathrm{~s}$. Microspheres were collected via centrifugation. 
Fig. 1 Microfluidic setup. PEGDA prepolymer aqueous droplet phase (pink) and hydrophobic mineral oil with acetophenone-NVP carrier phase (blue) were passed through a 4-junction microfluidic chip. Resulting droplets were photopolymerized with white light after exiting the chip and collected into centrifuge tubes (containing media if cells were included)

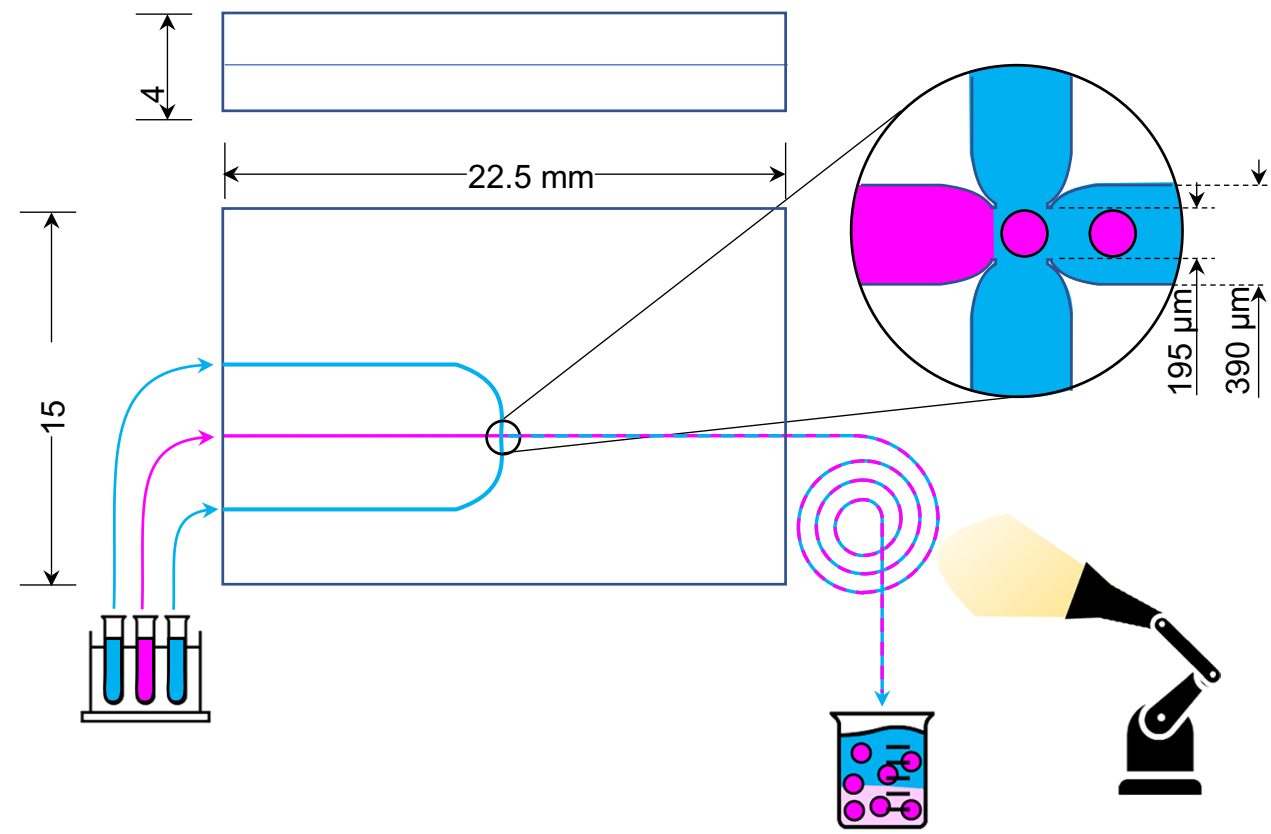

\section{Cell Viability}

Microparticles were centrifuged to pellet the microencapsulated cells, and the supernatant was removed. A $50 \mu \mathrm{L}$ aliquot of encapsulated cells was collected from the center of each pellet and added to a 24 well black-walled plate containing $200 \mu \mathrm{L}$ of LIVE/DEAD® Viability/Cytotoxicity kit (Molecular Probes, Life Technologies) assay mix. The final concentrations of calcein acetoxymethyl (AM) and ethidium homodimer-1 (EthD-1) in complete culture media were $2 \mu \mathrm{M}$ and $4 \mu \mathrm{M}$, respectively. The samples were incubated in the calcein AM/EthD-1 media solution at $37{ }^{\circ} \mathrm{C}, 5 \% \mathrm{CO}_{2}$ for $20 \mathrm{~min}$ and then imaged on a fluorescent microscope.

\section{Image Analysis}

Droplet formation was recorded with video captured at $500 \mathrm{~Hz}$. Droplet diameters and frequencies were calculated using Dolomite droplet monitoring analysis software. Samples were imaged in low light conditions under brightfield imaging with a yellow filter on the illuminating light to minimize any polymerization before or after the outlet tubing. Polymerized microparticles were sampled and imaged on a glass slide before and after the placement of a second glass slide to help distinguish between liquid and polymerized particles.

Cells were imaged using an Olympus CellR imaging system comprising an inverted Olympus IX81 microscope, $10 \times 0.4$ NA lens (Olympus), Polychrome V illuminator (Till photonics), and ORCA ER interline CCD camera (Hamamatsu). Calcein was excited at $488 \mathrm{~nm}(10 \mathrm{~nm}$ bandwidth), with emission collected through a 525/40 bandpass filter; ethidium homodimer-1 was excited at $570 \mathrm{~nm}$, with emission collected through a 607/36 bandpass filter.

Images were processed using the ImageJ-win64 Fiji application. The signal intensities for calcein AM and EthD-1were normalized across samples to $1800-4095$ and 200-2000, respectively. A composite image was created for each sample by overlaying and merging fluorescent images with brightfield images. Individual microspheres in images were assessed for cell viability using NIH ImageJ where percent viability was calculated to be live cells divided by total cells.

\section{Results}

\section{Droplet Generation}

A wide variety of flow ratios were investigated (Fig. 2), which were controlled by adjusting the pressure on the carrier and droplet phases. These flow ratios caused the two fluids to exhibit either dripping, which produces stable droplet formation, or jetting, which is an annular or side-by-side flow of the two fluids that occurs when the flow rates of the two phases are increased beyond a certain point.

Stable PEGDA prepolymer droplets approximately 60-240 $\mu \mathrm{m}$ were formed (

Figure 3). Droplets larger than $190 \mu \mathrm{m}$ were not spherical in the microfluidic chip but were spherical in the outlet tubing. The droplet size was influenced by the ratio of droplet flow rate to carrier flow rate, which was in turn influenced by droplet-to-carrier pressure. There were no instances of 


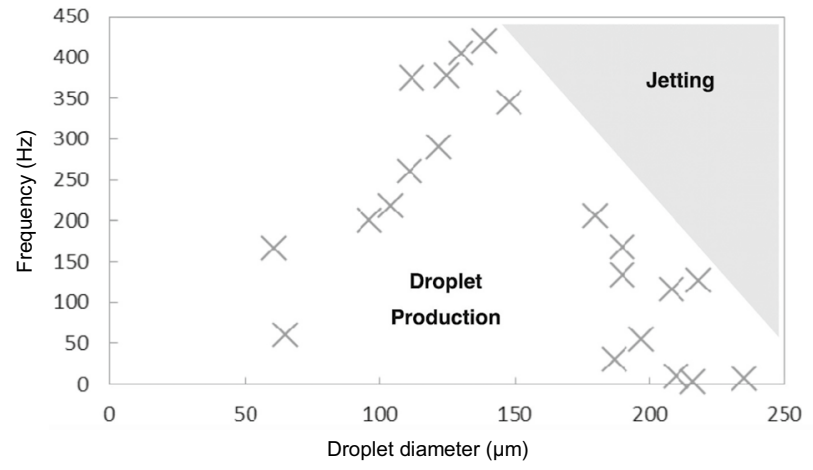

Fig. 2 The frequency and sizes of droplets that were produced over a range of flow rates

wetting of the microfluidic chamber by the aqueous phase over the hydrophobic phase.

\section{Droplet Polymerization into Microspheres}

The droplet residence time is the amount of time the droplet spends in the outlet tubing during illumination. It can be defined as

$\tau=V_{\text {tubing }} /\left(Q_{\mathrm{d}}+Q_{\mathrm{c}}\right)$

where $\tau$ is droplet residence time, $V_{\text {tubing }}$ is the volume of the tubing, and $Q_{\mathrm{d}}$ and $Q_{\mathrm{c}}$ are the flow rate of the droplet and the carrier, respectively. Samples from Fig. 3 are obtained following illumination with the metal halide white light and their level of photopolymerization was assessed.

Tests 1-10 are in order of decreasing time spent illuminated in the outlet tubing, with zero illumination in test 10. The length of the outlet tubing remains unchanged; therefore, the flow rate dictates how long a droplet spends in the polymerization section. Correspondingly, a visual difference exists between particles produced. For instance, samples from test 1 have sharp defined edges with rough surface features. In contrast, samples from test 8 have smooth surfaces and appeared relatively more flexible when slides were placed upon them.

Samples from tests 1 to 4 demonstrated a high degree of polymerization (Fig. 4). When sandwiched between glass slides, microspheres forced together maintain a discrete line demarcating the edge boundary. Samples from tests 5 to 8 showed successively lower degrees of polymerization indicated by fusing of microsphere boundaries. This merging is indicative of a fluid layer present on the outside of the microsphere that may not have fully polymerized. This fluid layer appears to be easily removable by resuspension in aqueous medium and subsequent washing. Samples from tests 5 to 8 appear to exhibit greater compliance than the apparently stiffer samples from tests 1 to 4 as evidenced by the fact that the test 5-8 "Sandwiched" images are proportionately larger than their "Open" images. The reduced residence time correlates well with these changes in elastic behavior (i.e., from stiffer to less stiff), which is further representative of degree of polymer cross-linking.

Samples from test 9 show the limiting condition at which no further polymerization is achieved. In this test, both the carrier and droplet phase were pumped at 7 bar each. The resulting high flow through the outlet tubing provided insufficient time ( $\tau=15 \mathrm{~s})$ for polymerization. As a result, the output sample collapsed when the glass slide was placed upon it and complete merging of neighboring droplets was observed.

Test 10 served as a control that was never illuminated by the metal halide lamp and therefore underwent no polymerization. The droplets appeared distinct but flattened and merged immediately when covered with glass slides.

The diameter of droplets and microspheres is related to the frequency of droplet formation (Fig. 5). In addition, the residence time is related to the frequency. Below a residence time of $69 \mathrm{~s}$, droplets did not polymerize. A residence time of $69 \mathrm{~s}$ corresponds to a frequency of $75 \mathrm{~Hz}$, which in turn corresponds to droplets and microspheres larger than $130 \mu \mathrm{m}$.

\section{Cell Microencapsulation}

Cells were microencapsulated and then sampled and imaged. Some samples contained microspheres but did not contain any cells (Fig. 6A). Other samples contained cells, but no microspheres (Fig. 6B). Other samples contained both microencapsulated and non-encapsulated cells (Fig. 6C), while some samples contained cells microencapsulated into spherical and rounded pyramid-like shapes (Fig. 6D).

Qualitatively, it could be seen that microspheres formed using emulsion techniques had a higher density of cells than microspheres formed using microfluidics (Fig. 7A and B). In addition, microfluidic techniques produced microspheres with comparable sizes as the emulsion methods, but with a much narrower size distribution (Fig. 7C). The viability of cells microencapsulated into individual microparticles was $20 \pm 8 \%$ when using microfluidics and $95 \pm 0.5 \%$ when using emulsion techniques (Fig. 7D).

\section{Discussion}

In this work, we successfully generated PEGDA microspheres using microfluidic approaches. The sizes of the resulting microspheres (60-240 $\mu \mathrm{m}$ diameter depending on flow rate) were comparable to those achieved via batch colloidal emulsions prepared by our lab and others (20-300 $\mu \mathrm{m}$ diameter per batch) $[6,14,18]$. Moreover, 


\begin{tabular}{|c|c|c|c|c|c|c|c|}
\hline \multirow[b]{2}{*}{$\begin{array}{l}\text { Test } \\
\text { No. }\end{array}$} & \multicolumn{2}{|c|}{ Droplet } & \multicolumn{2}{|c|}{ Carrier } & \multirow{2}{*}{$\begin{array}{l}\text { Representative Image at } \\
\text { Microfluidic Chip }\end{array}$} & \multirow{2}{*}{$\begin{array}{c}\text { Diameter } \\
(\mu \mathrm{m})\end{array}$} & \multirow{2}{*}{$\begin{array}{l}\text { Formation } \\
\text { Rate }(\mathrm{Hz})\end{array}$} \\
\hline & $\begin{array}{c}\text { Pressure } \\
\text { (mbar) }\end{array}$ & $\begin{array}{c}\text { Flow rate } \\
(\mu \mathrm{L} / \mathrm{min})\end{array}$ & $\begin{array}{c}\text { Pressure } \\
\text { (mbar) }\end{array}$ & $\begin{array}{c}\text { Flow rate } \\
(\mu \mathrm{L} / \mathrm{min})\end{array}$ & & & \\
\hline 1 & 500 & 0.87 & 500 & 13.64 & & 167 & 6 \\
\hline 2 & 1000 & 1.92 & 1000 & 32.60 & & 153 & 17 \\
\hline 3 & 1500 & 2.39 & 1500 & 41.78 & $\mathrm{O}$ & 149 & 23 \\
\hline 4 & 2000 & 3.51 & 2000 & 60.70 & ) & 145 & 37 \\
\hline 5 & 3000 & 5.78 & 3000 & 106.39 & 0 & 127 & 81 \\
\hline 6 & 3000 & 5.93 & 3000 & 112.98 & $\mathrm{O} \mathrm{O}$ & 127 & 92 \\
\hline 7 & 4000 & 7.23 & 4000 & 151.89 & 2000 & 114 & 139 \\
\hline 8 & 5000 & 9.09 & 5000 & 194.02 & 00000 & 110 & 220 \\
\hline 9 & 6000 & 10.45 & 6000 & 247.58 & 000000 & 101 & 325 \\
\hline 10 & 7000 & 14.51 & 7000 & 286.44 & 0000 & 101 & 440 \\
\hline
\end{tabular}

Fig. 3 Testing conditions and results of droplet tests 
Fig. 4 Droplet polymerization following illumination with white light. Compression with the second glass slide increases the apparent radius of the polymerized droplets. At high residence times, droplets polymerized into hydrogel microspheres. With decreasing residence time, droplets did not fully polymerize and remained partially or completely liquid, coalescing to varying degrees when sandwiched between glass slides. Samples from test 10 were control samples that were not illuminated

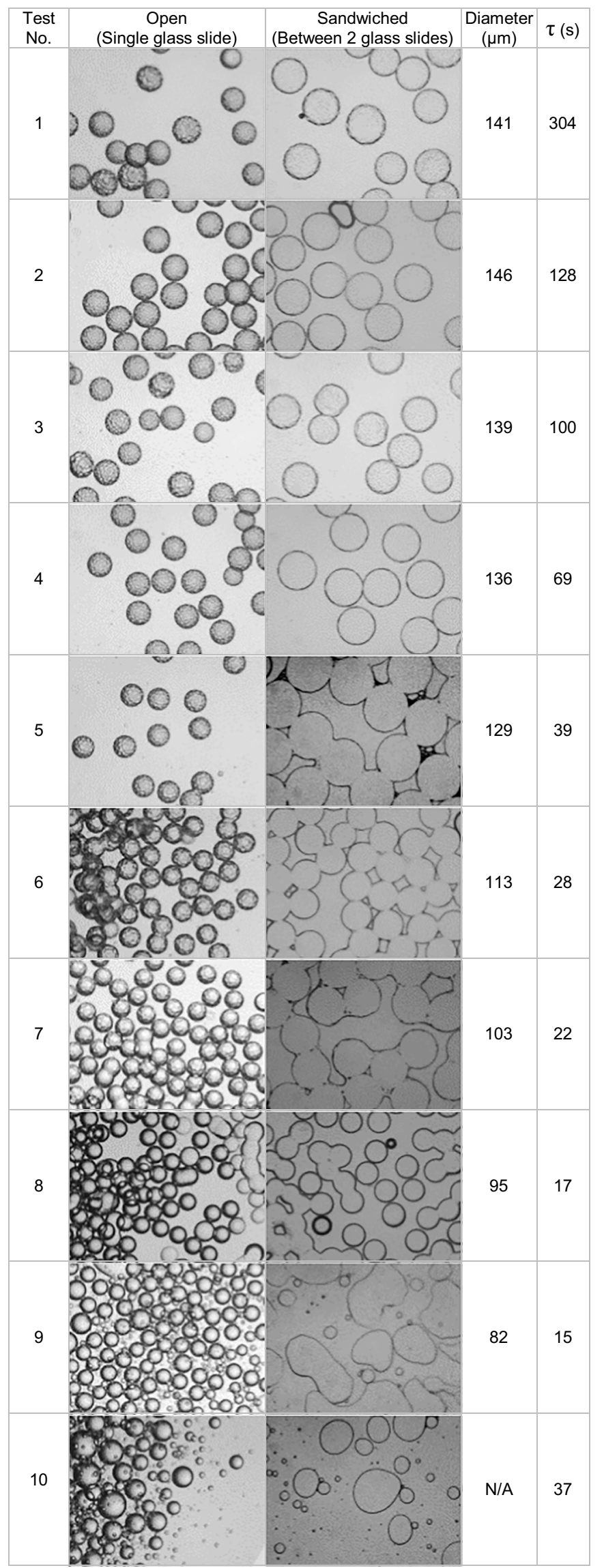


Fig. 5 Droplet size and residence time versus frequency

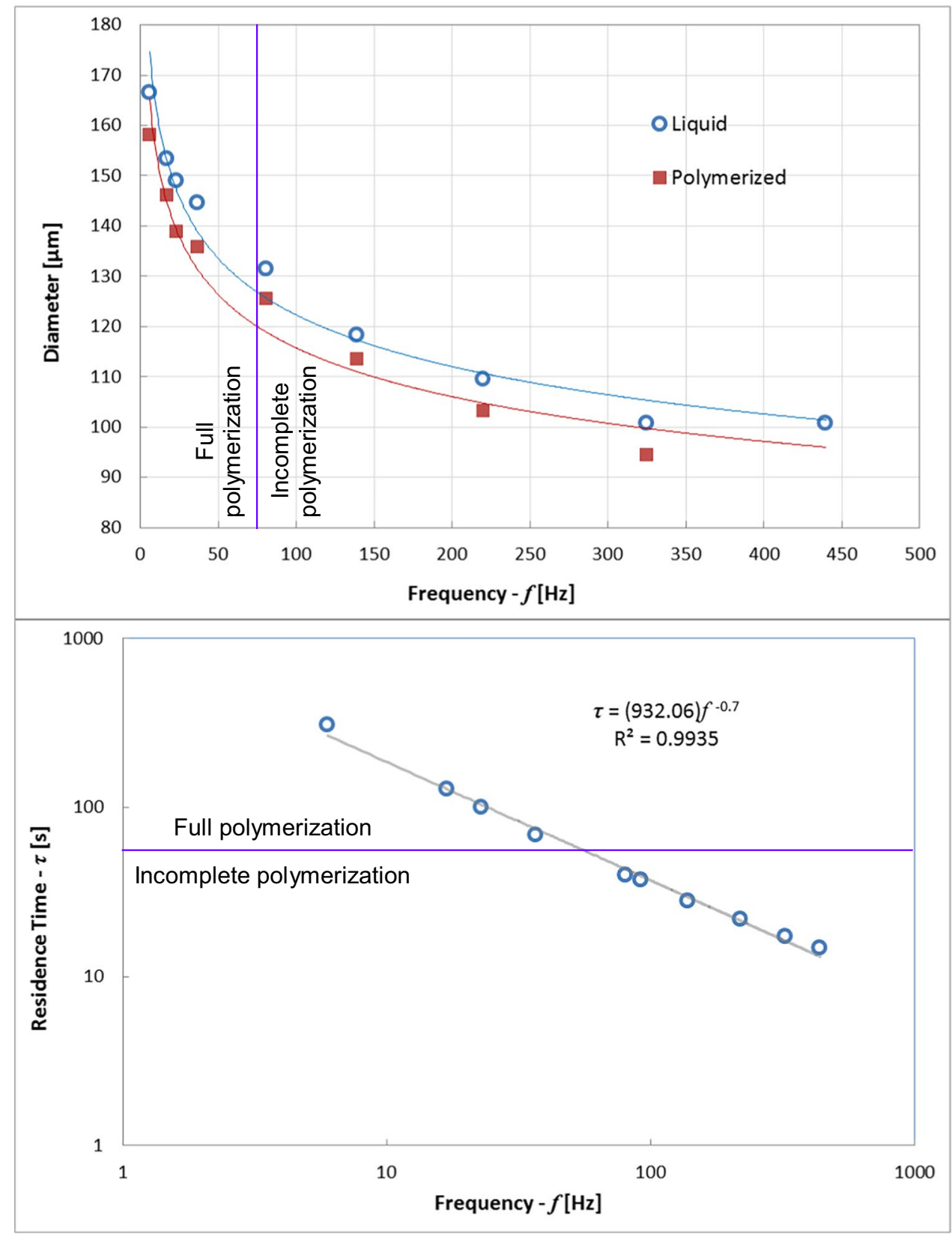

unlike the photopolymerized emulsions, microfluidic approaches yielded monodisperse microspheres with sizes that could be tuned by modulating the frequency of microsphere generation.

Although we also demonstrated that microfluidics can be used to encapsulate cells into PEGDA microspheres, the results were inconsistent. Other pioneering work demonstrated that microfluidics could be used to encapsulate human lung adenocarcinoma epithelial cells (A549) into PEGDA hydrogel microspheres [20, 23, 24]. Although these studies established the potential of microfluidics, adenocarcinoma cells are robust cells that survive conditions that other cells do not. Additionally, these methods encapsulated cells at low cell densities. Furthermore, many of those microspheres were devoid of cells. Because our goal was to encapsulate a high density of cells, a high concentration of cells was introduced into the prepolymer solution. Unfortunately, this did not translate into a high density of cells encapsulated into microspheres. When cells are introduced into the prepolymer solution, the cells aggregate and clog the microfluidic channels. The clogged cells cause a buildup of pressure, which leads to sudden rapid unplugging of the clogged channels, resulting in empty microspheres and unencapsulated cells. Even when aggregation does not lead to clogging, the presence of the high number of cells appears to alter the final shape of the microparticles and 
Fig. 6 Results of microfluidic encapsulation of cells. A Microspheres with no cells. B Cells with no microspheres. C A mix of encapsulated and unencapsulated cells. D Encapsulated cells only

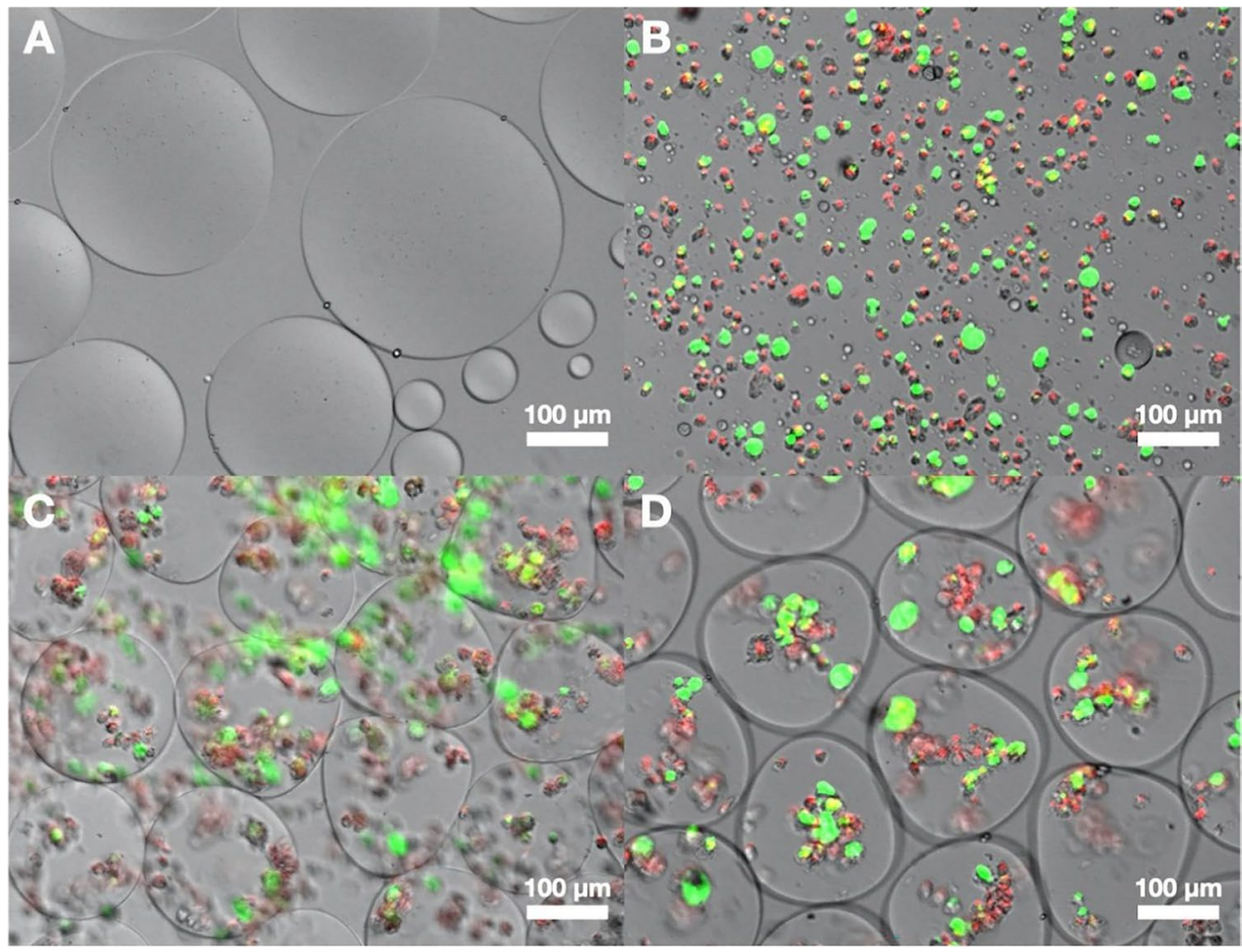

the dynamics of the photopolymerization process. In traditional colloidal systems, such as vortex mixing, the cells occupy a smaller percentage of the total volume; thus, their contribution to the fluid dynamics of the system is lessened compared to the carrier phase(s). However, in microfluidic systems, the carrier phase volume fraction is greatly reduced. Adding a high number of dissociated cells to the aqueous phase changes the colloidal properties within the microfluidic chamber and alters the photochemistry kinetics of the prepolymer solution. It is possible that the presence of cells and cellular material are also altering the interfacial tension between the phases. These changes in interfacial tension and fluid dynamics may combine to result in a reduction of sphericity as the product exits the channel.
Fig. 7 Comparison of emulsion vs microfluidic encapsulation of cells. A Representative cells microencapsulated using emulsion techniques. B Representative cells microencapsulated using microfluidic techniques. C Distribution of micrometer sizes using microfluidic and emulsion methods. D Viability of encapsulated cells using microfluidic $(20 \pm 8 \%)$ and emulsion $(95 \pm 0.5 \%)$ methods were statistically distinct (p $<0.05$ ) when compared using a student's t-test. Error bars show standard deviation
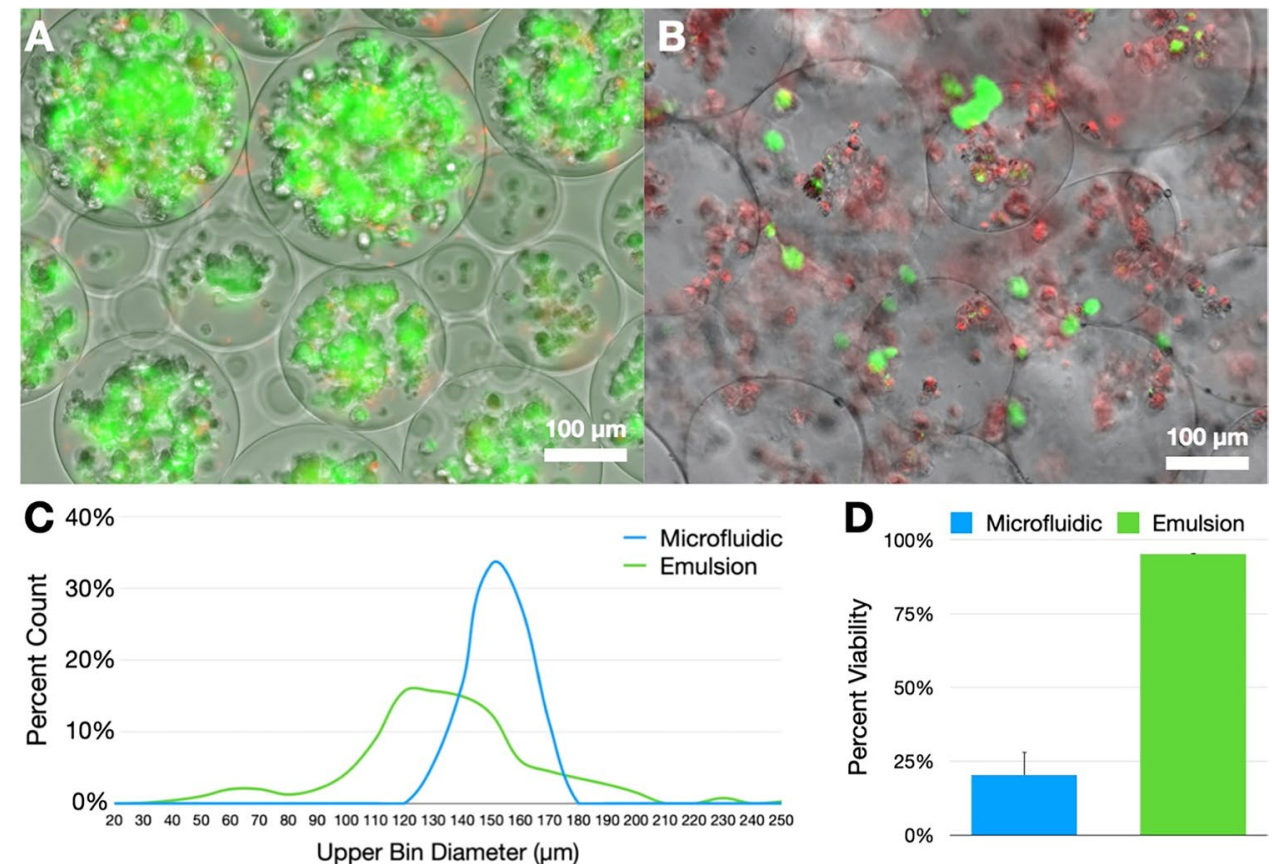
Finally, the viability of microfluidic-encapsulated cells was well below that of emulsion-encapsulated cells (20 vs $95 \%$ ), which was consistent with what we previously reported for emulsion-encapsulated cells $[6,18]$. We previously demonstrated that a variety of cell types require their own optimal cell density to thrive when encapsulated into hydrogel microspheres [6]. The clogging observed occurred when prepolymer was mixed with cells at densities comparable to those achieved in bulk microencapsulationities. It is likely that lower cell densities would result in less cell aggregation and in turn reduced clogging of the channels. Indeed, others have demonstrated successful microfluidic encapsulation of cells at low densities [20, 23, 24]. Thus, for applications requiring singly encapsulated cells, microfluidic approaches may be suitable. For applications requiring densely encapsulated cells, further work is needed to devise methods to prevent cell aggregation and clogging of the microfluidic devices.

Availability of Data and Material Data is available upon reasonable request.

Code Availability Not applicable.

\section{Declarations}

Conflict of Interest The authors declare no competing interests.

Open Access This article is licensed under a Creative Commons Attribution 4.0 International License, which permits use, sharing, adaptation, distribution and reproduction in any medium or format, as long as you give appropriate credit to the original author(s) and the source, provide a link to the Creative Commons licence, and indicate if changes were made. The images or other third party material in this article are included in the article's Creative Commons licence, unless indicated otherwise in a credit line to the material. If material is not included in the article's Creative Commons licence and your intended use is not permitted by statutory regulation or exceeds the permitted use, you will need to obtain permission directly from the copyright holder. To view a copy of this licence, visit http://creativecommons.org/licenses/by/4.0/.

\section{References}

1. Nicodemus GD, Bryant SJ. Cell encapsulation in biodegradable hydrogels for tissue engineering applications. Tissue Eng Part B Rev. 2008;14:149.

2. Bryant SJ, Vernerey FJ. Programmable hydrogels for cell encapsulation and neo-tissue growth to enable personalized tissue engineering. Adv Healthcare Mater. 2018;7:1700605.

3. Hunt NC, Grover LM. Cell encapsulation using biopolymer gels for regenerative medicine. Biotech Lett. 2010;32:733.

4. Chang TMS. ARTIFICIAL CELL evolves into nanomedicine, biotherapeutics, blood substitutes, drug delivery, enzyme/gene therapy, cancer therapy, cell/stem cell therapy, nanoparticles, liposomes, bioencapsulation, replicating synthetic cells, cell encapsulation/scaffold, biosorbent/immunosorbent haemoperfusion/plasmapheresis, regenerative medicine, encapsulated microbe, nanobiotechnology, nanotechnology. Artif Cells Nanomed Biotechnol. 2019;47:997.

5. Wu D-Q, Sun Y-X, Xu X-D, Cheng S-X, Zhang X-Z, Zhuo R-X. Biodegradable and $\mathrm{pH}$-sensitive hydrogels for cell encapsulation and controlled drug release. Biomacromol. 2008;9:1155.

6. Perera D, Medini M, Seethamraju D, Falkowski R, White K, Olabisi RM. The effect of polymer molecular weight and cell seeding density on viability of cells entrapped within PEGDA hydrogel microspheres. J Microencapsul. 2018;35:475.

7. Orive G, Hernandez RM, Gascon AR, Calafiore R, Chang TM, De Vos $\mathrm{P}$, et al. Cell encapsulation: promise and progress. Nat Med. 2003;9:104.

8. Olabisi RM. Cell microencapsulation with synthetic polymers. J Biomed Mater Res, Part A. 2015;103:846.

9. Kang A, Park J, Ju J, Jeong GS, Lee S-H. Cell encapsulation via microtechnologies. Biomaterials. 2014;35:2651.

10. Tan WH, Takeuchi S. Monodisperse alginate hydrogel microbeads for cell encapsulation. Adv Mater. 2007;19:2696.

11. Ghidoni I, Chlapanidas T, Bucco M, Crovato F, Marazzi M, Vigo $\mathrm{D}$, et al. Alginate cell encapsulation: new advances in reproduction and cartilage regenerative medicine. Cytotechnology. 2008;58:49.

12. Phelps EA, Enemchukwu NO, Fiore VF, Sy JC, Murthy N, Sulchek TA, et al. Maleimide cross-linked bioactive peg hydrogel exhibits improved reaction kinetics and cross-linking for cell encapsulation and in situ delivery. Adv Mater. 2012;24:64.

13. Revzin A, Tompkins RG, Toner M. Surface engineering with poly (ethylene glycol) photolithography to create high-density cell arrays on glass. Langmuir. 2003;19:9855.

14. Franco C, Price J, West J. Development and optimization of a dual-photoinitiator, emulsion-based technique for rapid generation of cell-laden hydrogel microspheres. Acta Biomater. 2011;7:3267.

15. Mehta S, McClarren B, Aijaz A, Chalaby R, Cook-Chennault K, Olabisi RM. The effect of low-magnitude, high-frequency vibration on poly (ethylene glycol)-microencapsulated mesenchymal stem cells. Journal of tissue engineering. 2018;9:2041731418800101.

16. Mumaw J, Jordan ET, Sonnet C, Olabisi RM, Olmsted-Davis EA, Davis AR et al (2012) Rapid heterotrophic ossification with cryopreserved poly (ethylene glycol-) microencapsulated BMP2expressing MSCs. Int J Biomater 2012:11

17. White K, Chalaby R, Lowe G, Berlin J, Glackin C, Olabisi R. Calcein binding to assess mineralization in hydrogel microspheres. Polymers. 2021;13:2274.

18. Olabisi RM, Lazard ZW, Franco CL, Hall MA, Kwon SK, SevickMuraca EM, et al. Hydrogel microsphere encapsulation of a cellbased gene therapy system increases cell survival of injected cells, transgene expression, and bone volume in a model of heterotopic ossification. Tissue Eng Part A. 2010;16:3727.

19. Sonnet C, Simpson CL, Olabisi RM, Sullivan K, Lazard Z, Gugala $\mathrm{Z}$, et al. Rapid healing of femoral defects in rats with low dose sustained BMP2 expression from PEGDA hydrogel microspheres. J Orthop Res. 2013;31:1597.

20. Xia B, Krutkramelis K, Oakey J. Oxygen-purged microfluidic device to enhance cell viability in photopolymerized PEG hydrogel microparticles. Biomacromol. 2016;17:2459.

21. Aijaz A, Faulknor R, Berthiaume F, Olabisi RM. Hydrogel microencapsulated insulin-secreting cells increase keratinocyte migration, epidermal thickness, collagen fiber density, and wound closure in a diabetic mouse model of wound healing. Tissue Eng Part A. $2015 ; 21: 2723$.

22. Tumber A, Meikle M, Hill P. Autocrine signals promote osteoblast survival in culture. J Endocrinol. 2000;167:383.

23. Jiang Z, Xia B, McBride R, Oakey J. A microfluidic-based cell encapsulation platform to achieve high long-term cell viability 
in photopolymerized PEGNB hydrogel microspheres. Journal of Materials Chemistry B. 2017;5:173.

24. Xia B, Jiang Z, Debroy D, Li D, Oakey J. Cytocompatible cell encapsulation via hydrogel photopolymerization in microfluidic emulsion droplets. Biomicrofluidics. 2017;11:044102.

25. Yeo LY, Chang HC, Chan PP, Friend JR. Microfluidic devices for bioapplications. Small. 2011;7:12.
Publisher's Note Springer Nature remains neutral with regard to jurisdictional claims in published maps and institutional affiliations. 